Acta Theriologica 37 (3): 213 - 240, 1992.

PL ISSN $0001-7051$

\title{
Phenetic relationships among bats of the family Rhinolophidae
}

\author{
Wiesław BOGDANOWICZ
}

\begin{abstract}
Bogdanowicz W. 1992. Phenetic relationships among bats of the family Rhinolophidae. Acta theriol. 37: $213-240$.

Phenetic analyses, using the common-part-removed transformation of Wood (1983), were performed on $2.5-6.4 \%$ of the variance that describes morphometric differences among bats of the family Rhinolophidae. Two ordination methods, one clustering technique, and a minimum-spanning tree were employed to assess patterns of similarity among 62 species. Two major phenetic groups were revealed. One comprised Oriental and Australian species, whereas the other contained Ethiopian and Palaearctic taxa. On the basis of morphological similarity, all but one species were provisionally arranged in 11 phenetic groups: megaphyllus, rouxii, euryolis, pearsonii, philippinensis, trifolialus, fumigatus, ferrumequinum, capensis, euryale, and hipposideros. Mensural data were not sufficient to clarify the status of $R$. maclaudi. Based on the morphological dispersion analysis, the Oriental region should be regarded as the center of origin of the family. On the basis of phylogenetic and functional factors, a close ancestor of rhinolophids probably lived in tropical rain forests, flew slowly emitting low-frequency sounds, and caught relatively soft but large prey.

Mammal Research Institute, Polish Academy of Sciences, 17-230 Białowieża, Poland

Key words: Rhinolophidae, phenetic relationships, preliminary classification, center of origin, functional morphology
\end{abstract}

\section{Introduction}

The Recent family Rhinolophidae comprises the single genus Rhinolophus Lecépède, 1799, and consists of 64 species (Corbet and Hill 1991). Its systematics is complicated, owing to the large number of taxa from nearly all temperate and tropical regions of the Old World. Most studies of systematic affinities among the species of Rhinolophus (Tate and Archbold 1939) were based on trivial differences, primarily associated with noseleaf structure, the position of the anterior upper premolar $\left(\mathrm{P}^{2}\right)$, and general body size. Andersen (1905a, b, 1918) attempted the first detailed clarification of the taxonomy of the Rhinolophidae. Tate and Archbold (1939) and Tate (1943) summarized the synoptic arrangements proposed by Andersen (1905a, b, 1918), including more recently described forms. Since then, no general review of the family has appeared, and other investigators (Hill and Yoshiyuki 1980, Hill and Schlitter 1982, Meester et al. 1986, Lekagul and McNeely 1988, Yoshiyuki 1989, 1990) either accepted Andersen's point-of-view or made only minor changes in his classification. It is, therefore, not surprising that 
the entire family requires a broad revision as was done for Mormoopidae (Smith 1972), Molossidae (Freeman 1981), Stenodermatinae (Owen 1987, 1988), Emballonuridae (Freeman 1989), and Phyllostomidae (Baker et al. 1989).

The purposes of this study were to examine phenetic associations within the Rhinolophidae via multivariate analyses of cranial and external mensural characters, and, in conjunction with other published data, to construct a new classification for the family. The classification of any group should be based on estimates of genealogy rather than phenetics. Nevertheless, phenetic classifications may assess objectively relative similarity of taxa - a determination of high intrinsic interest to taxonomists. "The history of taxonomy decisively refutes the assumption that similarity is self-evident and not in need of careful evaluation" (Mayr 1969: 201).

\section{Materials and methods}

Species, specimen s, and me asu rem ents. Analyses were based on 903 skins and skulls (listed in Bogdanowicz and $O$ wen 1992) representing 62 species. This included two samples of $R$. ferrumequinum ( $R$. f. ferrumequinum from Europe and $R$. f. nippon (rom Japan) and two samples of $R$. luctus (from India and Sri Lanka, and southeast Asia). Specific designations follow those of Koopman (1982) and Corbet and Hill (1991), with the exception of $R$. sinicus and $R$. formosae. Karyology (Ands et al. 1980, Dulic 1980, Naidu and Gururaj 1984, Zhang 1985, Zima et al. in press) and bacular morphology (Topal 1975) indicate that these two taxa should be treated as valid species.

My goal was to examine at least 5 adult specimens of each species. In some instances, 5 specimens were not available, but for some species, I measured more than 10 individuals. Most specimens were complete and intact, with no missing characters. Only specimens with fully assified metacarpalphalangeal epiphyses were included in the analysis.

Measurements were taken with dial calipers to the nearest $0.05 \mathrm{~mm}$ and $0.1 \mathrm{~mm}$ for cranial and external dimensions, respectively. A total of 35 ( 19 cranial and 16 external) characters were examined (Table 1). With the exceptions noted below, cranial and external measurements follow those of Rautenbach (1986) and Freeman (1981), respectively. Bullar width was measured from the inner margin of the bulla, perpendicularly to the lateral margin of the external auditory meatus. Metacarpal length equaled the distance between the proximal and distal end of the bone, excluding the wrist. The length of the last phalanx of the third, fourth, and fifth digits excluded cartilaginous tips; the hindfoot was measured excluding claws.

Transformations and phenetic procedures. In general, Owen (1988) was followed for transformation and phenetic procedures. All values were transformed to their natural logarithms and the arithmetic mean of each character was then calculated for each species.

Wood (1983) described a common-part-removed transformation for phenetic analysis of continuous data that involves regression of the vector of character values from each species on analogous vector(s) for one or more closely related species. In my study, the vector of character values for each species was regressed on that for Aselliscus tricuspidatus. This species is a member of the Hipposideridae, the sister family to the Rhinolophidae. Based upon microcomplement fixation data from transferrin, Aselliscus can even be treated as a sister genus for Rhinolophus (Pierson 1986). For each species, the vector of residual values was retained. These vectors were combined and used as the transformed data matrix. All further mathematical operations were performed based on this matrix.

Two ordination and one clustering methods evaluated phenetic variation in cranial and external body characters. Nonmetric multidimensional scaling based on average taxonomic distances (Sneath and Sokal 1973, Abbott et al. 1985) was calculated from the transformed data matrix. In this 
procedure, axes are computed so that the intertaxon distances in the reduced space bear as nearly a monotonal relationship to the intertaxon distances in the original matrix as possible. An advantage of multidimensional scaling over most other ordination methods is that distortion of intertaxon relationships is not concerned among closely related taxa; rather, the method provides balance between large intercluster distances and smaller within cluster-distances (Owen 1988).

Principal-components analysis of a character variance-covariance matrix using unstandardized data was used to ordinate taxa. Rather than minimizing stress (as with multidimensional scaling), principal-components analysis is designed to explain the maximum percentage of the matrix variation with a given number of orthogonal components. An advantage is that the components are interpretable in terms of individual character loadings. Character loadings were scaled by dividing the eigenvectors by the standard deviation of the characters, and multiplying the quotient by the square root of the eigenvalue (van Zyll de Jong 1984). A minimum-spanning tree (Sneath and Sokal 1973, Abbott et al. 1985) computed from the average taxonomic distance matrix was superimposed onto the three-dimensional plots from multidimensional scaling and principal-components analyses to further elucidate relationships among species.

Unweighted pair-group method using arithmetic averages (Sneath and Sokal 1973) was used to cluster taxa into phenetic groups. This analysis was performed on the matrix of average taxonomic distances computed from the transformed data matrix. Cophenetic correlation coefficients, matrix correlations, and correlations among cophenetic and correlation matrices resulting from all ordination and clustering methods were also calculated (Sneath and Sokal 1973, Rohlf 1974). Matrix correlations from ordination methods are analogous to cophenetic correlations for clustering procedures, being computed as a measure of the agreement between species-similarity values from the threedimensional projections and those from the transformed-distance matrix (Owen 1988).

Ordination and cluster analysis were conducted on all 64 rhinolophid taxa (n $\geq 1$ ) and on a reduced data set of 50 taxa $(n \geq 5)$. Males and females within species were pooled to increase the number of taxa which met the last criterion ( $\mathrm{n} \geq 5$ ).

Morphological d j persion. A simple way to express the morphological dispersion of a fauna is to determine each taxon's average phenetic distance to every other taxon in the fauna, sum the averages, and calculate the faunal average (Findley 1973, 1976; Freeman 1981). A low average distance for a species indicates phenetic similarity to most of the bats in the fauna. The average taxonomic distances between every pair of species in a fauna were computed based on a matrix of standardized residuals. The Kruskal-Wallis nonparametric test was used to evaluate differences among average launa] values. Because no nonparametric multiple range test exists for unequal sample sizes, the Mann-Whitney $U$-test was conducted on all pair-wise combinations of the four faunas. Rhinolophus ferrumequinum (Japan) and $R$. luctus (India and Sri Lanka) were removed from the analysis because they were represented in the sample by conspecifics from Europe and southeast Asia for which sample sizes were larger. Geographic affiliations of rhinotophid groups were based on Wallace's zoogeographical divisions (Lincoln $e t$ a $l$. 1982).

Computer programs were from the NTSYS-pe (version 1.6) and STATGRAPHICS (version 5.0) packages.

\section{Results}

\section{Phenetic relationships}

The common-part-removed transformation removed $93.6 \% \quad(R$. mehelyi) to 97.5\% ( $R$. megaphyllus and $R$. thomasi) of the total variation of each species' character vector (Bogdanowicz and Owen 1992). Phenetic analyses were performed on the remaining variance that describes the morphometric differences among rhinolophids. 
Table 1. Character loadings and percent variance for the first three principal components from principal-components analyses $[64(n \geq 1)$ and $50(n \geq 5)]$ taxa based on the character variancecovariance matrix.

\begin{tabular}{|c|c|c|c|c|c|c|}
\hline \multirow{2}{*}{ Character } & \multicolumn{3}{|c|}{$64 \operatorname{taxa}$} & \multicolumn{3}{|c|}{50 taxa } \\
\hline & I & II & III & I & II & III \\
\hline Greatest skull length & 0.687 & 0.172 & -0.483 & 0.861 & -0.254 & -0.185 \\
\hline Condylocanine length & 0.666 & 0.264 & -0.493 & 0.845 & -0.337 & -0.114 \\
\hline Breadth of braincase & 0.417 & -0.581 & -0.378 & 0.429 & 0.184 & -0.743 \\
\hline Mastoid breadth & 0.602 & -0.445 & -0.090 & 0.533 & 0.347 & -0.430 \\
\hline Zygomatic breadth & -0.154 & -0.260 & -0.648 & -0.033 & -0.387 & -0.710 \\
\hline Least interorbital breadth & 0.274 & -0.779 & 0.456 & -0.078 & 0.926 & -0.139 \\
\hline Breadth of nasal swellings & 0.355 & -0.031 & -0.412 & 0.476 & -0.115 & -0.212 \\
\hline Height of braincase & 0.295 & -0.710 & 0.076 & 0.113 & 0.620 & -0.454 \\
\hline Length of maxillary toothrow & 0.400 & 0.274 & -0.750 & 0.710 & -0.496 & -0.291 \\
\hline Width across upper canines & -0.393 & 0.137 & -0.769 & -0.099 & -0.713 & -0.500 \\
\hline Width across upper third molars & 0.036 & -0.247 & -0.805 & 0.238 & -0.356 & -0.786 \\
\hline Supraorbital length & 0.533 & 0.393 & 0.090 & 0.606 & -0.029 & 0.441 \\
\hline Palatal length & 0.176 & 0.558 & 0.715 & -0.009 & 0.075 & 0.879 \\
\hline Breadth of foramen magnum & 0.336 & -0.809 & 0.099 & 0.092 & 0.679 & -0.514 \\
\hline Bullar width & 0.589 & -0.507 & 0.231 & 0.383 & 0.631 & -0.216 \\
\hline Greatest length of mandible & 0.173 & 0.460 & -0.726 & 0.519 & -0.704 & -0.145 \\
\hline Length of mandibular toothrow & 0.297 & 0.283 & -0.774 & 0.620 & -0.560 & -0.323 \\
\hline Hejght of mandibular ramus & -0.807 & 0.206 & -0.168 & -0.698 & -0.443 & 0.050 \\
\hline Coronoid-angular distance & -0.854 & 0.253 & -0.199 & -0.724 & -0.524 & -0.036 \\
\hline Forearm length & 0.742 & -0.245 & -0.031 & 0.620 & 0.222 & -0.246 \\
\hline Third digit, metacarpal length & 0.834 & -0.283 & -0.059 & 0.755 & 0.302 & -0.334 \\
\hline Third digit, first phalanx length & -0.595 & 0.210 & 0.355 & -0.597 & -0.082 & 0.416 \\
\hline Third digit, second phalanx length & -0.879 & 0.038 & -0.053 & -0.818 & -0.336 & -0.098 \\
\hline Fourth digit, metacarpal length & 0.707 & -0.320 & 0.153 & 0.522 & 0.402 & -0.243 \\
\hline Fourth digit, first phalan $x$ length & 0.690 & -0.052 & 0.075 & 0.622 & 0.226 & 0.188 \\
\hline Fourth digit, second phalanx length & -0.903 & -0.106 & 0.133 & -0.914 & -0.141 & -0.048 \\
\hline Fifth digit, metacarpal length & 0.629 & -0.075 & -0.044 & 0.523 & -0.062 & -0.163 \\
\hline Finh digit, first phalanx length & 0.167 & -0.529 & 0.372 & -0.181 & 0.565 & -0.006 \\
\hline Fifth digit, second phalanx length & -0.531 & 0.221 & 0.383 & -0.582 & 0.045 & 0.408 \\
\hline Total length & -0.444 & -0.178 & 0.102 & -0.396 & 0.298 & -0.018 \\
\hline Tail length & -0.596 & -0.282 & 0.453 & -0.668 & 0.529 & 0.186 \\
\hline Ear length & 0.219 & 0.434 & 0.496 & 0.177 & 0.038 & 0.762 \\
\hline Greatest breadth of horseshoe & 0.486 & 0.668 & -0.094 & 0.690 & -0.295 & 0.417 \\
\hline Tibia length & 0.024 & 0.492 & -0.459 & 0.298 & -0.599 & -0.171 \\
\hline Hindfoot length & -0.435 & 0.360 & -0.220 & -0.272 & -0.573 & 0.007 \\
\hline Variance explained (\%) & 31.60 & 19.34 & 17.58 & 34.19 & 21.06 & 14.96 \\
\hline
\end{tabular}

In the principal-components analysis, the first three components explained almost $69 \%$ of the variance (component I, $31.6 \%$; II, $19.3 \%$; and III, $17.6 \%$ ). Of the 35 characters, 15 loaded heavily (absolute values $>0.550$ ) on component $I$; nine were positive (Table 1). Thus, nearly half of the characters distinguished two 
groups of rhinolophids, with several species more or less dispersed around and between them (Fig. 1A). The cluster on the left side of the figure comprised mostly horseshoe bats from the Ethiopian and Palaearctic regions. All species lying between $R$. mehelyi (41), $R$. ferrumequinum (22, 23), $R$. hildebrandtii (27), $R$. silvestris (52), $R$. swinnyi (59), and probably $R$. simulator (54) belong to this group. Oriental $R$. luctus $(33,34), R$. trifoliatus $(62), R$. sedulus (50), and Ethiopian $R$. maclaudi (35) occur along the posterior edge of the cluster.

The second cluster prineipally comprised Oriental and Australian species. Within this cluster, a group of more than 20 closely associated species can be distinguished that are similar morphologically. The group, which is bordered by $R$. monoceros (42), $R$. virgo (63), $R$. simplex (53), $R$. osgoodi (43), $R$. toxopei (61), $R$. keyensis (30), and $R$. feae (21), creates the nucleus of this cluster. In this group, only two species are known from the Palaearctic: $R$. cornutus (13) from the Manchurian subregion (if $R$. c. pumilus is treated as a distinct species as defined by Yoshiyuki, 1989) and the Oriental $R$. lepidus (32), which is found also in the Manchurian and Mediterranean subdivisions of the Palaearctic region. Near the border of the nucleus is $R$. stheno (56). The remaining species, with $R$. rufus (49), $R$. pearsonii (44), $R$. yunanensis (64), $R$. subrufus (58), R. philippinensis (45), $R$. cognatus (12), $R$. macrotis (36), and $R$. marshalli (39) in the background, are farther from the central part of the cluster. This is true for $R$. gracilis (25), as well as for a group of five species $[R$. affinis (2), $R$. acuminatus (1), $R$. sinicus (55), $R$. rouxii (48), and $R$. thomasi (60)] that occupy an intermediate position between the first and second clusters. Six characters load heavily on component II (two positive, four negative; Table 1). Nevertheless, the overall morphological resemblance of rhinolophids is so high that component II does not create evident groups. This component separates only $R$. luctus $(33,34)$ and $R$. trifoliatus $(62)$ from the first major cluster (as defined by component $I$ ), and $R$. rufus (49), $R$. yunanensis (64), $R$. pearsonii (44), and $R$. subrufus (58) from the second cluster. All of these species have long palates and wide horseshoes. Conversely, they have narrower braincase breadths, the smallest interorbital breadths, heights of braincase, and foramen magnum widths. The influence of the third component is visible especially among species from the Oriental and Australian regions. This component differentiates $R$. philippinensis (45), $R$. macrotis (36), R. marshalli (39), and Ethiopian $R$. maclaudi (35) from all other rhinolophids. These four species exhibit longer palates, narrower skulls at the zygomatic arches and across the upper third molars, as well as shorter maxillary toothrows, mandibles, and lower mandibular rami. Contrasting morphological traits occur in $R$. affinis (2), $R$, acuminatus (1), $R$. rouxii (48), $R$. sinicus (55), $R$. thomasi (60), and $R$. stheno (56).

In the nonmetric multidimensional scaling of 64 taxa, axis I (Fig. 1B) suggests the existence of three clusters. Both negative and positive ends of the diagram are occupied by Oriental and Australian rhinolophids, whereas Ethiopian and Palaearctic species are intermediate between them. Nevertheless, all three clusters overlap and are not compact morphologically. The cluster at the negative 

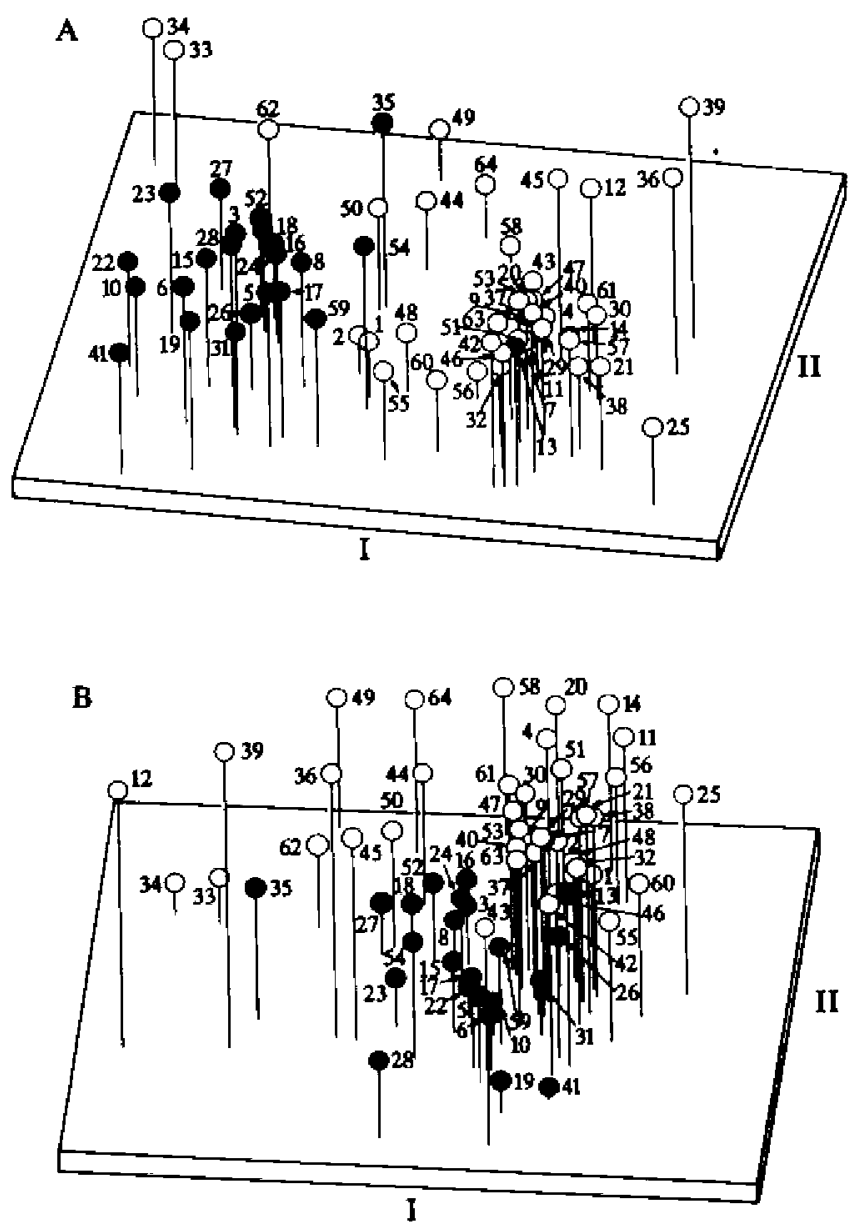

Fig. 1. (A) Projections of 64 taxa of Rhinolophus onto first three principal components from transformed data matrix. Component III indicated by height. (B) Projections of 64 taxa onto axes for three-dimensional nonmetric-multidimensional-scaling solution bascd on transformed data matrix. Axis III indicated by height. Stress value is 0.197 . Filled circles mark Ethiopian and Palacarctic taxa; open circles designate Australian and Oriental taxa. Species are: $1-R$. acuminalus; $2-R$. affinis; 3 $-R$. alcyone; $4-R$. arcuatus; $5-R$. blasii; $6-R$. bocharicus; $7-R$. borneensis; $8-R$. capensis; $9-$ $R$. celebensis; $10-R$. clivosus; $11-R$. coelophyllus; $12-R$. cognatus; $13-R$. cornulus; $14-R$. creaghi; $15-R$. darling $i ; 16-R$. deckenii; $17-R$. denti; $18-R$. eloquens; $19-R$. euryale; $20-R$. euryotis; $21-R$. feae; $22-R$. ferrumequinum (Europe); $23-R$. ferrumequinum (Japan); $24-R$. fumigalus; 25 $-R$. gracilis; $26-R$. guineensis; $27-R$. hildebrandtii; $28-R$. hipposideros; $29-R$. imaizumii; $30-$ R. keyensis; $31-R$. landeri; $32-R$. lepidus; $33-R$. luctus (SE Asia); $34-R$. luctus (India, Sri Lanka); $35-R$. maclaudi; $36-R$. macrolis; $37-R$. madurensis; $38-R$. malayanus; $39-R$. marshalli; $40-$ $R$. megaphyllus; $41-R$. mehelyi; $42-R$. monoceros; $43-R$. osgoodi; $44-R$. pearsonii; $45-R$. philippirensis; $46-R$. pusillus; $47-R$. robinsoni; $48-R$. rouxii; $49-R$. rufus; $50-R$. sedulus; $51-$ $R$. shameli; $52-R$. siluestris; $53-R$. simplex; $54-R$. simulator; $55-R$. sinicus; $56-R$. stheno; 57 $-R$. subbadius; $58-R$. subrufus; $59-R$. swinnyi; $60-$ R. thomasi; $61-R$. toxopei; $62-R$. trifolialus; $63-R$. virgo; $64-R$. yunanensis. 

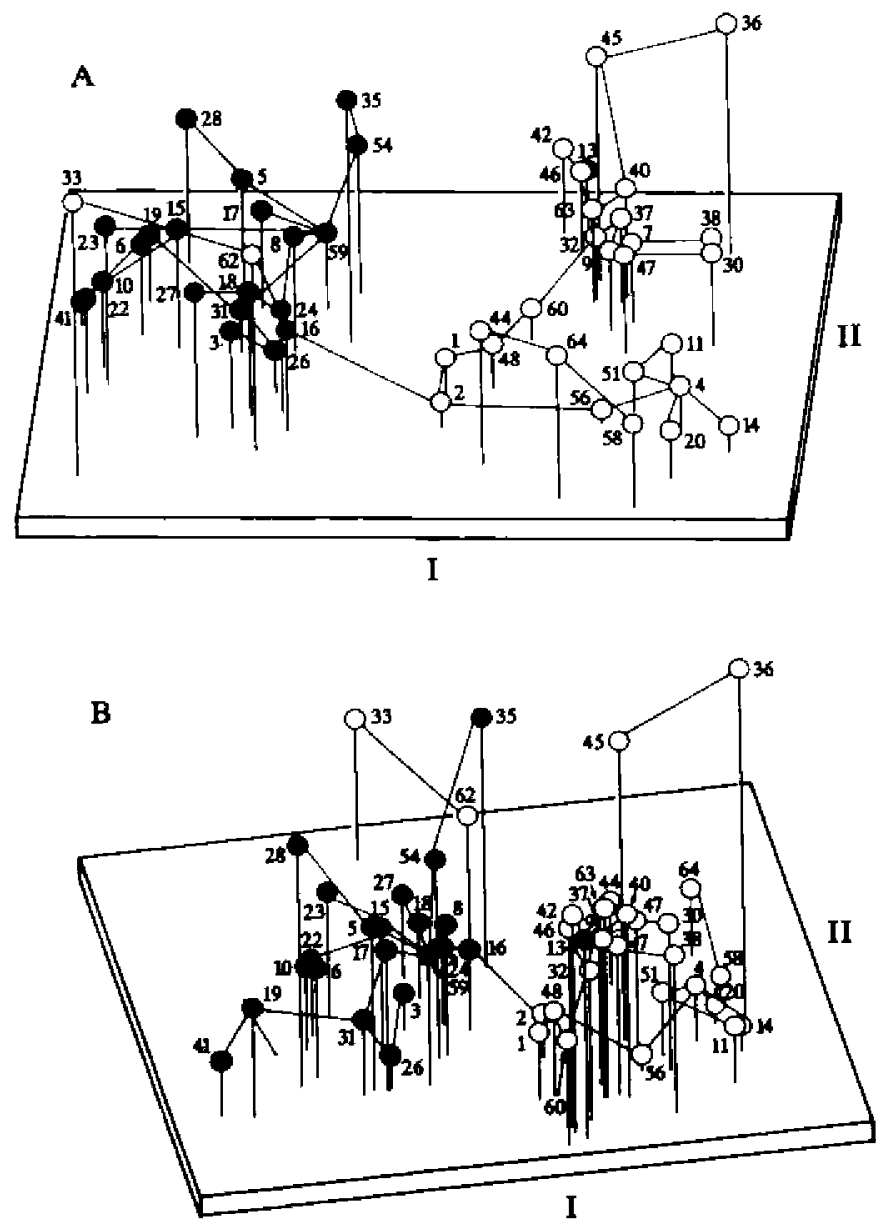

Fig. 2. (A) Projections of 50 taxa of rhinolophid bats onto first three principal components from transformed data matrix. Component III indicated by height. (B) Projections of 50 rhinolophid taxa onto axes of three-dimensional nonmetric-multidimensional-scaling solution. Axis III indicated by height. Stress value is 0.209 . Both plots with the minimum-spanning trec superimposed. Filled circles mark Ethiopian and Palaearctic taxa; open circles designate Australian and Oriental taxa. Species numbered as in Fig. 1 ,

end is most heterogenous, particularly with respect to axis III. As component I in the principal-components analysis, axis III distinguishes Ethiopian and Palaearctic species from most of Oriental and Australian rhinolophids. Based on this axis, Rhinolophus luctus $(33,34)$ and $R$. trifoliatus $(62)$ occur among Ethiopian and Palaearctic species. Rhinolophus sedulus (50) is at an intermediate position between $R$. trifoliatus ( 62 ) and $R$. pearsonii (44); $R$. sedulus, however, is connected to $R$. trifoliatus (62) on the minimum-spanning tree. 
Table 2. Cophenetic correlation coefficients, matrix correlations, and correlations between cophenetic and correlation matrices resulting from all clustering and ordination procedures. Values in upper right half from analyses with 64 taxa $(n \geq 1)$; those in lower left from analyses of 50 taxa $(n \geq 5)$.

\begin{tabular}{|c|c|c|c|c|}
\hline & $r$ & $\begin{array}{l}\text { Unweighted } \\
\text { pair-group method } \\
\text { using arithmetic } \\
\text { averages }\end{array}$ & $\begin{array}{c}\text { Nonmetric } \\
\text { multidimensional } \\
\text { scaling }\end{array}$ & $\begin{array}{l}\text { Principal- } \\
\text { components } \\
\text { analysis }\end{array}$ \\
\hline$r$ & & 0.782 & 0.973 & 0.898 \\
\hline $\begin{array}{l}\text { Unweighted pair-group method } \\
\text { using arithmetic averages }\end{array}$ & 0.782 & & 0.753 & 0.678 \\
\hline $\begin{array}{l}\text { Nonmetric multidimensional } \\
\text { scaling }\end{array}$ & 0.970 & 0.752 & & 0.905 \\
\hline $\begin{array}{l}\text { Principal-components analysis } \\
\text { (onvariance matrix) }\end{array}$ & 0.939 & 0.754 & 0.962 & \\
\hline
\end{tabular}

Ordination of 50 taxa with $n \geq 5$ produced two distinct clusters of species located along axis I (Fig. 2), which correspond to the zoogeographic affinities of the taxa. The first three principal components account for $34.2,21.1$, and $15.0 \%$ of total variance, respectively. Sixteen characters load heavily on component I; nine are positive (Table 1). The second principal component shows five positive and five negative character loadings. Generally, this component divides the species group from southern Asia and Australia into two large subgroups which occupy exclusive portions of the morphospace (Fig. 2A). Such distinctiveness is especially evident when the minimum-spanning tree is superimposed on the three dimensional diagram. The results of multidimensional scaling of 50 taxa are not uniform, yet the existence of two subgroups for Oriental and Australian bats is confirmed (Fig. 2B). In both ordination analyses, the third axis segregates $R$. philippinensis (45), $R$. macrotis (36), and R. maclaudi (35) from Australian and Oriental as well as from Ethiopian and Palaearctic groups (Fig. 2). All these species [and $R$. luctus (33) with $R$. trifoliatus (62) (Fig. 2A)] exhibit relatively narrower skulls in their zygomatic and rostral parts, longer palates, and longer ears (Table 1).

As expected, the cluster analysis produced lower matrix correlations than did ordination methods (Table 2). Also, the cophenetic correlation was low indicating appreciable distortion in the phenograms. The phenogram of 64 taxa from the average taxonomic distance matrix indicated the existence of three major clusters within the family (Fig. 3). Two of these clearly relate to ordination results. Oriental and Australian species are grouped in the first cluster, whereas mostly Ethiopian and Palaearctic taxa are in the second cluster. A third cluster includes $R$. macrotis (36), $R$. marshalli (39), $R$. philippinensis (45), and $R$. osgoodi (43).

The first major cluster is divided into five (or possibly six) smaller groups. An assemblage comprising $R$. acuminatus (1), $R$. rouxii (48), $R$. sinicus (55), and $R$. 


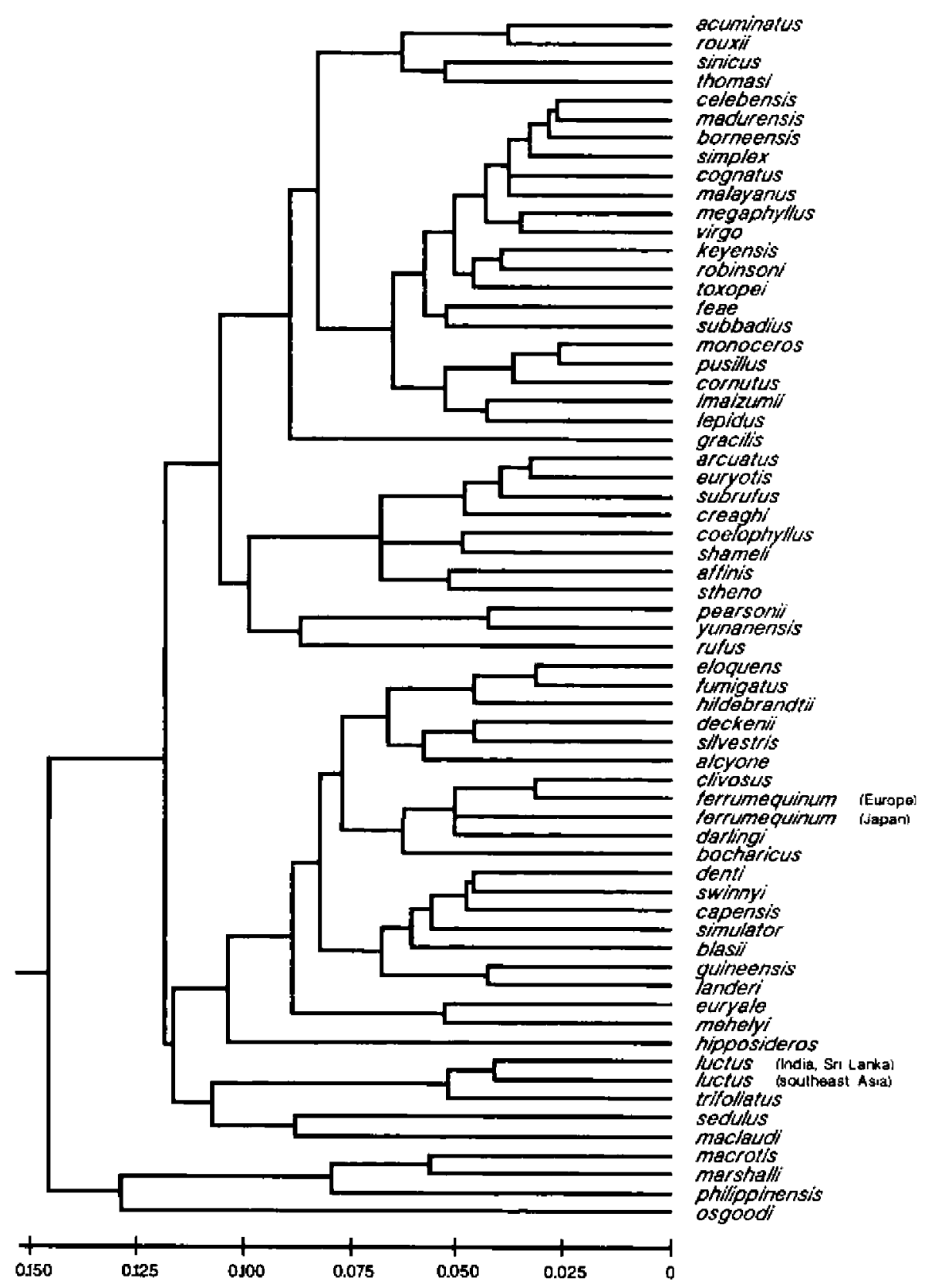

Fig. 3. Phenogram (unweighted pair-group method using arithmetic averages) for average taxonomic distances calculated from transformed data matrix, with 64 taxa of Rhinolophus included. 


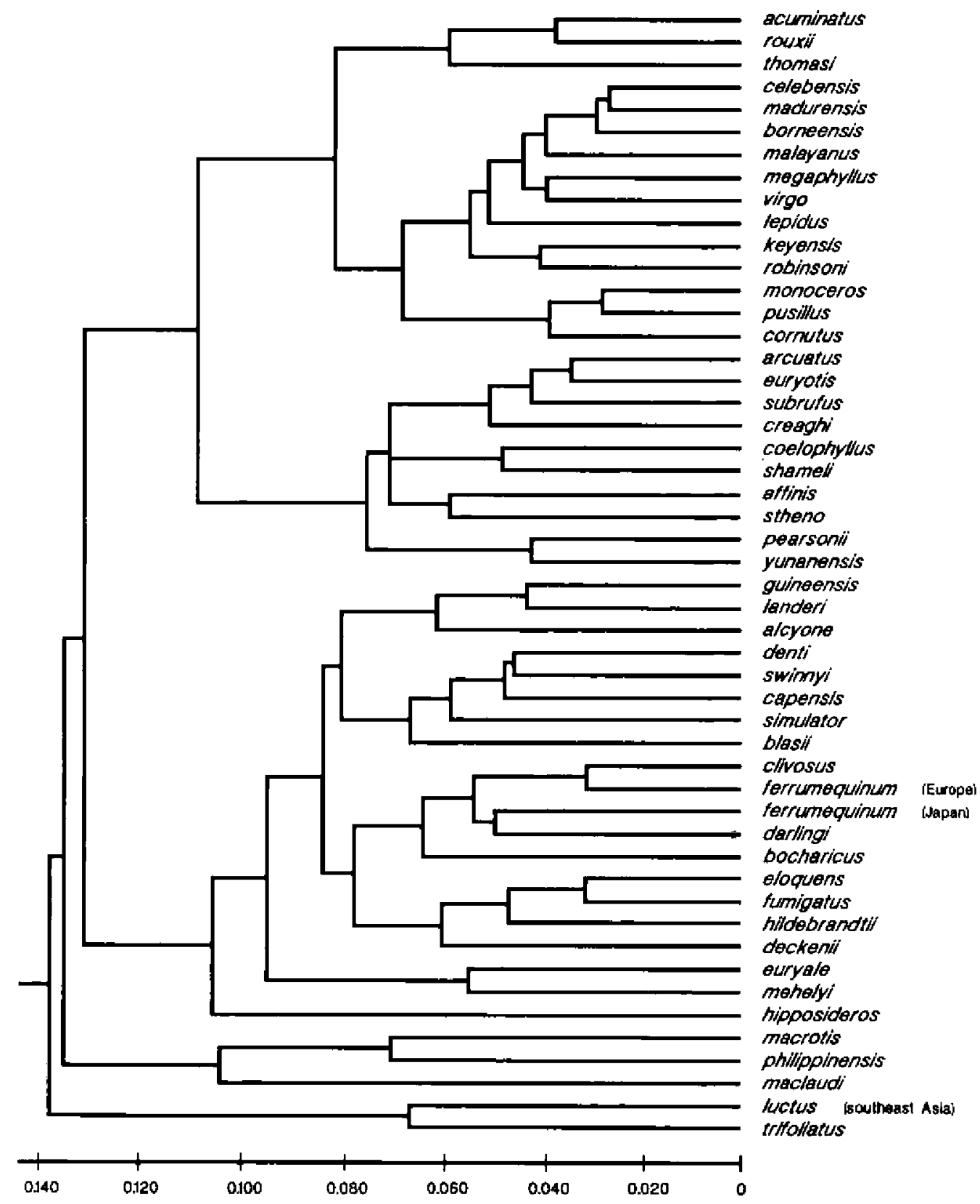

Fig. 4. Phenogram (unweighted pair-group method using arithmetic averages) for average taxonomic distances calculated from transformed data matrix, with 50 taxa of rhinolophid bats included. 
thomasi $(60)$ is located in the middle of principal component I (Fig. 1A). The corresponding minimum-spanning tree confirms that these species are close neighbors (Fig. 2). Despite its location with $R$. stheno (56) on the phenogram (Fig. $3), R$. affinis may be also allied with this group. The next group in the phenogram comprises two subgroups, with 13 and 5 species, respectively. Both groups are compact and occupy similar morphospace in the principal-components analysis. The next group contains $R$. gracilis (25) only, a species from southeast India. Another group, comprising eight taxa [R. arcuatus (4), R. euryotis (20), R. subrufus (58), R. creaghi (14), R. coelophyllus (11), R. shameli (51), R. stheno (56), and $R$. affinis (2)] has a complex structure. Phenetically, $R$. affinis (2), as indicated by the ordination results, is nearest to $R$, acuminatus (1). Two morphologically similar species, $R$. pearsonii (44) and $R$. yunanensis (64), and probably $R$. rufus (49), form a separate group. The position of $R$. rufus (49) is not clear as it is isolated from its neighbors. Nonetheless $R$. rufus (49) appears to have more morphological similarities with $R$. pearsonii (44) and $R$. yunanensis (64) than any other horseshoe bats (Fig. 1).

The second major cluster contains several groups. The upper part of this cluster is occupied by $R$. eloquens (18), R. fumigatus (24), R. hildebrandtii (27), R. deckenii (16), $R$, silvestris (52), and probably $R$, alcyone (3). Rhinolophus clivosus (10), $R$. $f$. ferrumequinum (22), R. f. nippon (23), R. darlingi (15), and $R$. bocharicus (6) form another association. Small African rhinolophids, $R$, denti (17), $R$. swinnyi (59), $R$. capensis (8), $R$. simulator (54), and $R$. blasii (5), as well as $R$. guineensis (26) and $R$. landeri (31), occur in a separate complex. Two west Palaearctic species with close affinities, $R$. euryale (19) and $R$. mehelyi (41), seem to be sufficiently distinct morphologically to form another group. Because it is widely divergent from the previous species, $R$. hipposideros (28) can be considered as a monotypic group (see also Fig. 1B). The remaining eight taxa in the lower part of the phenogram represent two or perhaps three separate phenetic assemblages. Rhinolophus trifoliatus $(62)$ and $R$. luctus $(33,34)$ and probably $R$. maclaudi (35) and $R$. sedulus (50) should be included into one assemblage. African $R$. maclaudi (35) shows greater phenetic similarity to Asiatic $R$. trifoliatus (62) and $R$. luctus $(33,34)$ than to $R$. sedulus $(50)$ from Malaya and Borneo.

The third major cluster is formed by $R$. macrotis (36), $R$. marshalli (39), and $R$. philippinensis (45). The affinity of $R$. osgoodi (43) is unclear.

The pattern obtained from the cluster analysis of the reduced data set (Fig. 4) is similar to that in the phenogram based upon 64 taxa (Fig. 3). Several exceptions exist. Rhinolophus lepidus (32) is associated with $R$. celebensis (9), $R$. madurensis (37), R. borneensis (7), R. malayanus (38), R. megaphyllus (40), and $R$. virgo (63), whereas in the previous analysis (Fig. 3 ) this species had the closest affinities with $R$. imaizumii (29). The $R$. landeri (31) and $R$, guineensis (26) cluster includes $R$. alcyone (3), whereas the cluster with $R$. macrotis (36) and $R$. philippinensis (45) contains $R$. maclaudi (35). 


\section{Morphological dispersion}

Based on the Kruskal-Wallis nonparametric test, a significant difference $(p<0.001$ ) was found among the average distance values of the four faunas (Fig. 5). More specifically, pair-wise comparisons indicate that the Oriental fauna was more dispersed than are the Australian and Ethiopian faunas (Mann-Whitney
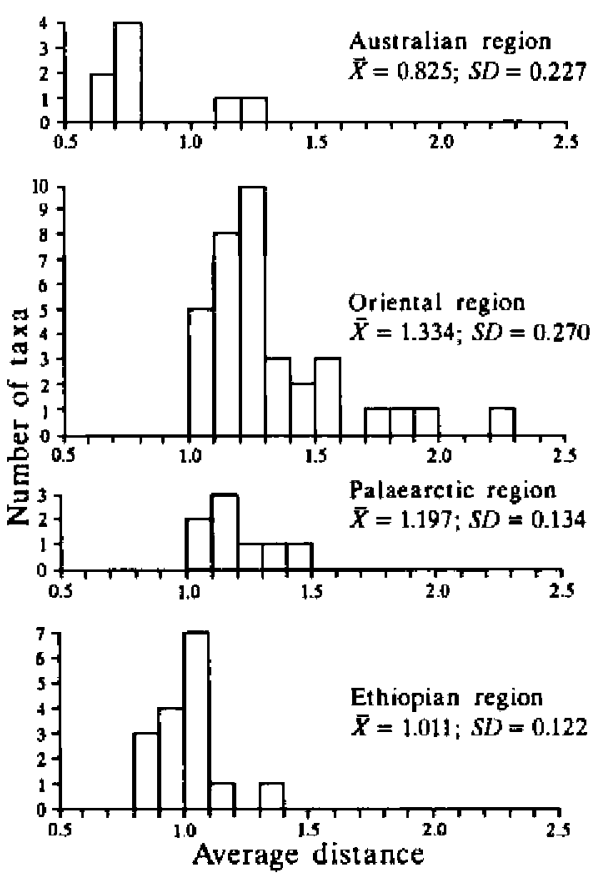

Fig. 5. Distribution of average taxonomic distances in four rhinolophid faunas.

$U$-test; $p<0.001$ ) and the Palaearctic fauna was more dispersed than the Ethiopian $(p<0.01)$ or Australian $(p<0.05)$ faunas. The Ethiopian fauna was statistically more dispersed than was the Australian fauna $(p<0.05)$. Although the Oriental fauna contains the most distinctive rhinolophid species (R. luctus and $R$. marshalli), no significant differences in dispersion obtained between the Oriental and Palaearctic faunas $(p=0.15)$.

\section{Discussion}

The extreme morphological similarity of horseshoe bats represents a major problem in the intrafamilial classification of rhinolophids. This similarity is expressed by the exceptionally low average taxonomic distances within the family $(0.023$ to 0.148 ; Fig. 3$)$. In comparison, the average taxonomic distances between stenodermatines (Phyllostomidae) ranged from 0.033 to 0.227 (Owen 1988: Fig. 1). This similarity is also indicated by the relatively small variance remaining after the common-part-removed transformation (2.5 - 6.4\%; Bogdanowicz and 
Owen 1992). Within the Stenodermatinae, this ranged from 1.3 to $13.8 \%$ (Owen 1988), whereas for three data sets on birds (Ciconiidae, Gruinae, and Emberizinae) it was $1.8-9.2 \%$ (Wood 1983). Consequently, division of Rhinolophidae should concern superspecies (Andersen 1905a) rather than subgenera (Gray 1866, Peters 1867, 1871; Matschie 1901).

\section{Australian and Oriental taxa}

It is constructive to compare the relationships of the taxa of Rhinolophus proposed by Andersen (1905a, b, 1918), and Tate and Archbold (1939), with the results of this analysis (Table 3 ). All three suggest a close association among $R$. arcuatus, $R$. subrufus, $R$. creaghi, $R$. euryotis, $R$. coelophyllus, and $R$. shameli on one hand, and among $R$. rouxii, $R$. sinicus, and $R$, thomasi on the other. Good morphological concordance exists between the Asiatic simplex and lepidus groups of Andersen (1905a) and my megaphyllus group. In all the morphological analyses, $R$. hipposideros was sufficiently distinct to be considered a separate monotypic group.

The differences between previous classifications and that suggested herein are more significant than are sole similarities (Table 3). My phenetic classification divides species into groups that are concordant with a zoogeographic classification. Species from the Palaearctic and Ethiopian regions generally are not associated with Oriental or Australian bats. A special place is held by representatives of the philippinensis group and $R$. macrotis from the macrotis group sensu Andersen (1905a). These rhinolophids are characterized by an unusually large and complicated noseleafs (Andersen 1905d, e) as well as by relatively low frequency vocalizations (Heller and Helversen 1989). However, R. luctus, $R$. trifoliatus, and $R$. maclaudi, in respect to overall morphological similarity, clearly differ from $R$. philippinensis, $R$, macrotis, and $R$. marshalli. The first three species cluster with Ethiopian and Palaearctic bats, whereas $R$. philippinensis, $R$. macrotis, and $R$. marshalli are typical Australian and Oriental forms (Figs 1A and 2). These species were provisionally classified into two different groups (Table 3), a position supported by Gray (1866), who already in the 19th century, separated $R$. luctus and $R$. trifoliatus from $R$. philippinensis, recognizing them as separate subgenera, Aquias and Phyllotis, respectively (Hill 1972).

Andersen (1905e) divided the philippinensis group into three sections: philippinensis, sedulus, and trifoliatus. Rhinolophus maclaudi was treated as an Ethiopian offshoot of the philippinensis type, with more highly developed dentition, wing-structure, and mental grooves (Andersen 1905e). The minimum-spanning tree confirmed the phenetic distinctiveness of the philippinensis and trifoliatus groups (Fig. 2). For this reason, $R$. sedulus was considered a member of the same group as $R$. trifoliatus and $R$. luctus. Nonetheless, $R$. maclaudi was closer to African rhinolophids than to either $R$. luctus or $R$. trifoliatus.

The largest cluster of species constitutes the megaphyllus group (Table 3). Close affinities among $R$. celebensis, $R$. borneensis, and $R$. madurensis are well known 
Table 3. Comparisons of phenetic classifications of the Rhinolophidae. That of Tate and Archbold (1939) is concerned primarily with Oriental taxa. Question-mark indicates uncertain species position in the group.

\begin{tabular}{|c|c|c|}
\hline Andersen $(1905 a, b)$ & Tate and Archbold (1939) & Proposed classification \\
\hline 1 & 2 & 3 \\
\hline simplex group (= megaphyllus & ferrumequinum group & megaphyllus group \\
\hline group of Andersen 1918) & simplex subgroup & megaphyllus subgroup \\
\hline simplex & simplex & megaphyllus \\
\hline megaphyllus & megaphyllus & simplex \\
\hline keyensis & keyensis & keyentsis \\
\hline borneensis & borneensis subgroup & borneensis \\
\hline celebensis & borneensis & celebensis \\
\hline malayanus & celebensis & madurensis \\
\hline virgo & malayanus & malayanus \\
\hline nereis & virgo & robinsoni \\
\hline stheno & madurensis & virgo \\
\hline simulator & nereis & pusillus subgroup \\
\hline denti & stheno & pusillus \\
\hline $\operatorname{rouxii}$ & anderseni & ?gracilis \\
\hline$r$. sinicus & rouxii subgroup & cornutus \\
\hline thomasi & rouxii & subbodius \\
\hline capensis & sinicus & monoceros \\
\hline affinis & thomasi & cognatus \\
\hline clivosus & affinis subgroup & imaizumii \\
\hline darlingi & affinis & lepidus \\
\hline ferrumequinum & robinsoni & feae \\
\hline deckenii & ferrumequinum subgroup & ? osgoodi \\
\hline lepidus Group (= pusillus & ferrumequinum & rouxii group \\
\hline group of Andersen 1918) & lepidus group & rouxii \\
\hline (lepidus "subgroup" of & lepidus subgroup & sinicus \\
\hline Andersen $1905 \mathrm{~b}: 122$ ) & lepidus & thomasi \\
\hline lepidus & l. refulgens & ? affinis \\
\hline l. refulgens & feae & ?acuminalus \\
\hline (acuminatus subgroup & cognatus & euryotis group \\
\hline of Audersen 1918) & acuminalus & euryolis \\
\hline acuminatus & minor subgroup & arcuatus \\
\hline (pusillus subgroup of & pusillus & toxopei \\
\hline Andersen 1918) & cornutus & creaghi \\
\hline pusillus & c. pumilus & coelophyllus \\
\hline cornutus & perdilus & shameli \\
\hline c. pumilus & gracilis & subrufus \\
\hline gracilis & subbadius subgroup & ? rufus \\
\hline (garoensis subgroup of & subbadius & ? stheno \\
\hline Andersen 1918) & monoceros & pearsonit group \\
\hline subbadius & philippinensis gтoup & pearsonii \\
\hline monoceros & philippinensis subgroup & yunanensis \\
\hline
\end{tabular}


Table 3 - continued

\begin{tabular}{|c|c|c|}
\hline 1 & 2 & 3 \\
\hline blasii & philippinensis & capensis group \\
\hline landeri & mitratus & copensis subgroup \\
\hline euryale & sedulus subgroup & capensis \\
\hline mehelyi & sedulus & denti \\
\hline midas group (= hipposideros & trifoliatus subgroup & swinnyi \\
\hline group of Andersen 1918) & trifoliatus & simulator \\
\hline hipposideros & lactus & landeri subgroup \\
\hline philippinensis group ( $=$ luctus & macrolis subgroup & landeri \\
\hline group of Andersen 1918) & macrotis & guineensis \\
\hline philippinensis & pearsonii & ? alcyone \\
\hline milratus & rex & ? blasii \\
\hline maclaudi & arcuatus group & ferrumequinum group \\
\hline sedulus & ancuatus subgroup & ferrumequinum \\
\hline trifolialus & areualus & clivosus \\
\hline luctus & toxopei & bocharicus \\
\hline macrotis group & subrufus & $?$ darlingi \\
\hline macrolis & inops & fumigatus group \\
\hline hirsutus & creaghi & fumigatus \\
\hline fumigalus & c. canuli & eloquens \\
\hline eloquens & coelophyllus & hildebrandaii \\
\hline hildebrandtii & euryotis & $?$ deckenii \\
\hline pearsonii & euryotis subgroup & ? silvestris \\
\hline arcuatus group (= euryolis & euryotis & euryale group \\
\hline group of Andersen 1918) & & euryale \\
\hline arcualus & & mehelyi \\
\hline subrufus & & hipposideros group \\
\hline inpos & & hipposideros \\
\hline creaghi & & philippinensis group \\
\hline c. canuli & & philippinensis \\
\hline coelophyllius & & marshalli \\
\hline euryotis & & macrotis \\
\hline Incertae sedis & & trifolialus group \\
\hline \multirow[t]{5}{*}{ alcyone } & & trifoliatus \\
\hline & & luctus \\
\hline & & sedulus \\
\hline & & Incertac sedis \\
\hline & & maclaudi \\
\hline
\end{tabular}

(Goodwin 1979, Hill 1983, Bergmans and van Bree 1986), but negate the suggestion (Tate and Archbold 1939) of a close association between $R$. robinsoni and $R$. affinis (Table 3). According to host-parasite relationships, close systematic relationships occur between $R$. c. cornutus, $R$. c. orii, $R$. perditus, $R$. imaizumii, and $R$. monoceros (Sawada and Harada 1988). Bacular morphology also suggests close affinities among Asiatic representatives of the lepidus group of Andersen 
(1905a). For example, such similarities were found among $R$. c. cornutus, $R . c$. orii, $R$. c. pumilus, $R$. perditus, $R$. imaizumii (Yoshiyuki 1989), and $R$. lepidus (Topal 1975). As such, these taxa should be considered valid subgroup within the new megaphyllus group.

Herein, the rouxii subgroup of Tate and Archbold (1939) with the addition of $R$. acuminatus and $R$. affinis was recognized as a distinct group. Both ordination and cluster analyses confirm close phenetic relationships between typical members of the rouxii group and $R$. acuminatus. Morphological data do not argue against the inclusion of $R$. stheno in this group.

The composition of the proposed euryotis group, with the exception of $R$. stheno, corresponds to the group of the same name sensu Andersen (1918) and Tate and Archbold (1939). Rhinolophus stheno has been in the simplex group of Andersen (1905a); with $R$. nereis (Andersen 1905b) as an offshoot of the $R$. borneensis subgroup (Tate and Archbold 1939), or with $R$. malayanus (McFarlane and Blood 1986, Lekagul and McNeely 1988). Nevertheless, strongly and abruptly projecting nasal swellings distinguish $R$. stheno from the eastern species of the simplex group of Andersen (1905a). Additionally, the tail of $R$. stheno is short and considerably smaller than the lower leg, whereas the tail of $R$, rouxii and $R$. borneensis is longer than or equal to the length of lower leg (Andersen 1907). This description of $R$. stheno corresponds to characteristics of the arcuatus group (Andersen 1905a, c). On the basis of cluster analysis, the arcuatus group of Andersen (1905a) may also contain $R$. rufus (see also Hill and Schlitter 1982). In Andersen's classification (1905a), the arcuatus group is the only one that has no representatives in the Ethiopian region.

The placement of three species ( $R$. gracilis, $R$. toxopei, and $R$. osgoodi) in the proposed phenetic classification was not altered compared to current taxonomic position (Andersen 1905b, Hinton 1925, Sanborn 1939, Koopman 1989, Corbet and Hill 1991) even though my results suggested a different arrangement. In my material, these species were represented by 1-2 specimens only, and their phenetic associations are consequently tenuous.

\section{Ethiopian and Palaearctic taxa}

The classification of rhinolophids from the Ethiopian and Palaearctic regions (with the exception of $R$. maclaudi) is less problematic than that of the horseshoe bats from the remaining parts of the Old World. My division of African species from the ferrumequinum group (= simplex group of Andersen 1905a) agrees to a large extent with subgroups recognized by Aellen and Brosset (1968). They primarily based group recognition on differences in the size of the anterior upper premolar $\left(\mathbf{P}^{2}\right)$ and the position of the upper canine in relation to the last upper premolar $\left(\mathbf{P}^{4}\right)$. These authors differentiated two subgroups: ferrumequinum, containing $R$. ferrumequinum, $R$. clivosus, and $R$. darlingi; and capensis, containing $R$. capensis, $R$. denti, $R$. swinnyi, $R$. simulator, and $R$. adami. Koopman (1975) noted the desirability of uniting $R$. simulator, R. adami, R. denti, R. swinnyi, 
and $R$. capensis with $R$. clivosus, $R$. ferrumequinum, $R$. darlingi, $R$. silvestris, and $R$. deckenii within the ferrumequinum group (= simplex group of Andersen, 1905a). Conversely, differences among $R$. deckenii, $R$. silvestris, and $R$. clivosus in inflation of the masal sinus and the construction of the basisphenoid bridge make the first two species closer to $R$. darlingi than to $R$. clivosus. All three taxa show some similarity to the fumigatus-eloquens-hildebrandtii complex (Koopman 1975). In my classification $R$, darlingi is in the ferrumequinum group. Perhaps this species should be associated with $R$. deckenii and $R$. silvestris in a separate group, somewhat intermediate between the ferrumequinum and capensis groups ( $K$ F. Koopman, in litt.).

The phenetic differences among species within the lepidus group of Andersen (1905a) were greater than has been judged by others (Andersen 1918, Hill and Yoshiyuki 1980, Yoshiyuki 1990). On this basis, a separate group was established for $R$. euryale and $R$. mehelyi. Matschie (1901) and Andersen and Matschie (1904) allocated both species into a separate subgenus, Euryalus. Morphologically, $R$. blasi is closer to $R$. denti, $R$. swinnyi, $R$. capensis, and $R$. simulator than to any other horseshoe bats. However, $R$. blasii is relatively distant from these African taxa, and is linked with $R$. landeri and $R$. guineensis as well (Figs 3 and 4). According to recent opinion, $R$. blasii should be associated with the landeri subgroup, rather than with the capensis subgroup of the capensis group (K. F. Koopman, in litt.). Obviously, other independent data sets are needed to fully understand systematic relationships within the Rhinolophidae.

Phenetic versus phylogenetic relationships

Based on the maximum likelihood analyses of the same morphological data set, Bogdanowicz and Owen (1992: Fig. 2) produced a cladogram that could be treated as a working hypothesis of evolutionary relationships among horseshoe bats. Phylogenetic affinities within the family, as suggested by their cladogram, are surprisingly similar to phenetic relationships. Almost all members of the phenetic assemblages are closely related phylogenetically, especially within the megaphyllus, euryotis, pearsonii, fumigatus, euryale, hipposideros, philippinensis, and trifoliatus groups.

In the rouxii group, $R$. acuminatus has close phylogenetic affinities with $R$. rouxii, $R$. thomasi, and $R$. sinicus. Rhinolophus affinis is situated between $R$. rouxii and $R$. stheno. Rhinolophus stheno, however, appears to be a basal taxon for the euryotis group. Such surprising relations (Andersen 1905a, b, McFarlane and Blood 1986) are also recommended by phenetic analyses.

The ferrumequinum group was well-defined, although the evolutionary status of $R$. bocharicus was doubtful. In the cladogram, this species was closer to the euryale group than to the ferrumequinum group. Rhinolophus bocharicus, however, is frequently treated as a subspecies of $R$. clivosus (Aellen 1959, Gaisler 1971, Koopman 1982). Its baculum, in dorsal view, resembles a convex arrow head (Hanák 1969). Within the Rhinolophidae, only $R$. ferrumequinum and $R$. clivosus 
are characterized by similar bacular morphology (Topál 1958, 1975; Lanza 1959, Hanák 1969, Yoshiyuki 1989).

The present analysis indicates morphological distinction between the philippinensis and trifoliatus groups. These results match the phylogenetic results (Bogdanowicz and Owen 1992). In the cladogram, R. philippinensis, R. macrotis, and $R$. marshalli are close to the root in the cluster of typical Oriental and Australian bats. Rhinolophus trifoliatus, $R$. luctus, and $R$. sedulus from the Oriental region share a common ancestor with highly derived African taxa $(R$. silvestris, $R$. fumigatus, $R$. eloquens, $R$. hildebrandtii, and $R$. alcyone). The phylogenetic position of African $R$. maclaudi is especially interesting. The results of both phenetic and phylogenetic analyses show that $R$. maclaudi is more allied with African rhinolophids than to members of the philippinensis group of Tate and Archbold (1939). These results appear to support Laurent's (1940) opinion that $R$. maclaudi should be treated as an African type, isolated from other Asiatic bats (but see Fig. 1B). In view of the general complexity within the genus Rhinolophus it is premature to comment in more detail on the systematic and phylogenetic relationships of $R$. maclaudi (Aellen 1973, Smith and Hood 1980).

Phenetic, karyological, and electrophoretic concordance

Based on nondifferentially stained chromosomes of 21 species, Harada et al. (1985) proposed that the genus be divided into three groups based on diploid number: (1) $2 n=62$; (2) $2 n=58$; and (3) variable diploid numbers $(2 n=32-60)$ with large biarmed autosomes. Most species of Rhinolophus occurred in the first two groups, and only one species, $R$. luctus, had $2 \mathrm{n}=32$ (Harada et al. 1985). It has been postulated on the basis of correlations between conventional karyotypes with phylogenetic relationships assumed from morphological characters that the autosomes for the prototypic karyotype in Rhinolophus consisted of all acrocentric elements with $2 \mathrm{n}=62$ and $\mathrm{FN}=60$ (Andō et al. 1983, see also Zima et al. in press). An acrocentric composition of the primitive karyotype and the trend toward low diploid chromosome numbers have been suggested as characteristics of the families Phyllostomidae and Vespertilionidae (Baker and Bickham 1980). At present, 33 (or possibly 34) species have been karyotyped (Zima et al., in press). On the basis of the differences in diploid number and number of autosomal arms, the Rhinolophidae can be divided in to two large groups, one with $2 \mathrm{n}=62$ and $\mathrm{FN}$ $=60$; and the other with $2 \mathrm{n}=58$ and $\mathrm{FN}=60,62$, or 64 (M. Harada, in litt.). Other species or subspecies can be treated as offshoots of these groups. This division, with few exceptions, agrees with the morphological differentiation of Australian and Oriental bats from Ethiopian and Palaearctic ones. Most rhinolophids possessing a 62-chromosome karyotype are restricted to the IndoMalayan region. Species with a karyotype of 58 chromosomes occur in Africa, Europe, or Asia, north of the Himalayas. All remaining species with chromosome numbers of 60 , and 56 or lower, have arisen in east Asia (Zima et al., in press). Only two exceptions are known from this trend. First, the distribution of $R$. 
ferrumequinum $(2 \mathrm{n}=58)$ extends southward, inhabiting the regions from northern India to Japan. Second, $R$. hipposideros has different chromosome numbers in different geographic regions: 56 chromosomes in Bulgaria (Belcheva et al. 1990), Italy (Capanna et al. 1967), Czecho-Slovakia (Zima 1982), and Azerbaijdan (Fattaev and Kuliev 1978); 58 in Jordan (Qumsiyeh et al. 1986, 1988); and 62 in Kirghizia (Zima et al., in press).

Qumsiyeh et al. (1988) reported extensive genic divergence based on starch gel electrophoresis of 10 species of the $R$ hinolophidae. Systematic relationships within the Rhinolophidae based on electrophoretic data are in many aspects discordant with those based on morphological criteria. The matrix correlation coefficient between these two independent data sets was lower than 0.500 (author's calculation). In phenograms based on Rogers' distances, most surprising from a morphological point of view is the fact that $R$. cornutus and $R$. clivosus arose from ancestors with protein complements much like the present-day $R$. darlingi. These three species share a common ancestor with $R$. ferrumequinum. Furthermore, based on allozymic data, $R$. affinis is closer to $R$. malayanus than to $R$. acuminatus. Qumsiyeh et al. (1988) present three hypotheses account for the apparent lack of concordance between these data sets. Morphological relationships might be inaccurate because of the extreme morphological similarity among the Rhinolophidae. With respect to the electrophoretic data, inaccuracy could be related to the large genetic distances between taxa, high intraspecific variation, and lack of appropriate analysis for the presence or absence of alleles or character state transformation. Finally, the resuits of morphological and electrophoretic data may not be comparable because of their different resolution at different evolutionary levels (Arnold et al. 1982).

Morphological dispersion and center of origin

Findley (1976) reasoned that if this is true, than older faunas are phenetically diverse. The distributions of the faunal averages (Fig. 5) suggest that the Oriental fauna is the oldest; the Palaearctic and the Ethiopian faunas are of intermediate age; and the Australian fauna is the youngest.

These findings agree with palaeontological considerations. The family originated in the Old World tropics, probably in Africa or in southern Asia (Koopman 1970, Hall 1989). Based on fossil evidence, rhinolophids entered Africa at a late date (Mio-Pliocene of North Africa; Butler 1978). Australia was colonized by bats migrating from Asia through the Indonesian Archipelago and New Guinea (Tate 1946, Hamilton-Smith 1974, 1975; Hand 1984, Flannery 1989). Currently, only two rhinolophid species ( $R$. megaphyllus and $R$. philippinensis) occur in Australia. Their presence in the eastern part of the continent evidently represents a relatively recent arrival from New Guinea, perhaps during the Pliocene or Pleistocene (Archer et al. 1989). Flannery (1990) stated that the Rhinolophidae, unlike its sister family (Hipposideridae), appeared in New Guinea at a late date, most probably during the Pleistocene. The recent phylogenetic research suggests 
southeast Asia, not Africa, as a center of evolutionary origin of the family (Bogdanowicz and Owen 1992).

Functional morphology and its evolutionary significance

Measurements such as greatest length of the skull, condylocanine length, and forearm length, are highly positively correlated with the first principal component in the 64 taxa analysis (Table 1). Nevertheless, bats on the far negative end of the first axis have even bigger skulls and longer forearms than their counterparts on the positive end (Fig. 1A). For example, greatest length of the skull of $R$. $f$. ferrumequinum was $22.8 \mathrm{~mm}$, whereas that of $R$. marshalli was $18.3 \mathrm{~mm}$. However, relative to head and body length, the skull of the former species is smaller than that of $R$. marshalli ( 34.4 and $43.4 \%$, respectively). The first principal component evidently is a shape, not a size, factor (Sneath and Sokal 1973). Its interpretation must be based on ratios between suites of different characters. In this context, Ethiopian and Palaearctic rhinolophids have smaller skulls, higher mandibular rami, and longer coronoid-angular distances than do their Australian and Oriental counterparts. They also have relatively longer second phalanges and tails, but their forearms and metacarpals are shorter. Characters that covary with these traits, as evidenced by high loadings on the first principal component from the reduced data set, are lengths of the jaw and mandibular and maxillary toothrows. Those species with short jaws and toothrows exhibit relatively small skulls. These differences are important functionally. Bats with proportionally shorter heads (skulls) and teeth have poor access to larger prey (Fenton 1989). An individual with a lower coronoid process can open its jaw wider without mechanical interference with the eye socket (Vaughan 1972), a feature helpful in catching large insects. Relatively high mandibular rami, as well as small skull and jaw sizes, may limit the diet of Ethiopian and Palaearctic bats to contain relatively small prey. On the other hand, the development of the coronoid process and sagittal crest allows for increased leverage and larger jaw muscles. Increases in the temporal muscle are particularly important as adaptations to the increased stress of struggling or tougher prey and extensive use of canines (Maynard Smith and Savage 1959). Bats with high coronoid processes, mostly from the Ethiopian and Palaearetic regions, should have the ability to crush hard-shelled items such as beetles, whereas Australian and Oriental taxa, with low coronoid processes, should consume soft items such as moths (Freeman 1979).

Within the Rhinolophidae, the size of small premolars varies considerably (Topál 1979, Wołoszyn 1987). Nevertheless, these teeth show a greater degree of reduction in Ethiopian and Palaearctic bats, especially medium and large-sized taxa, than in Australian and Oriental rhinolophids. This tendency partially agrees with Freeman's (1979) suggestion that beetle specialists have fewer but bigger teeth. Unfortunately, the diet of horseshoe bats has not been studied in much detail. Rhinolophids caught in northern Thailand during the rainy season feed on swarming ants and beetles. Preference shifted to crickets and scarabaeid beetles 
in fruitgrowing areas of the southern part of the country (Nabhitabhata 1986). The diet of $R$. ferrumequinum in England varied seasonally, and consisted mainly of Lepidoptera (40.6\% by volume) and Coleoptera (33.2\%; Jones 1990). McNab (1971) and Kock (1973) considered particle size and food type as important axes of niche differentiation for congeners.

The first principal component corresponds with maneuverability and flight speed. All rhinolophids have short, broad wings (low aspect ratio) and large wing area in relation to the body-weight (low wing-loading; Norberg 1987). They can fly slowly within vegetated areas. Subtle differences in the wing design could cause different flight performance in different species. Most rhinolophids from the Ethiopian and Palaearctic regions have relatively short metacarpals and long phalanges in the fifth digit. The ratio of the length of the fifth digit metacarpal to the combined length of the phalanges may estimate the abilities of the wing to camber in different ways, by changing the angle of attack (Baagøe 1987). For two equally broad wings, the wing with a low fifth digit metacarpal: phalanges ratio has a higher camberability than does one with a high index. Ethiopian and Palaearetic bats, including similarly shaped Oriental $R$. luctus and $R$. trifoliatus, also have relatively long tails (Table 1 ), narrow wings (higher digit III/digit V ratio; $t=4.22$, d.f. $=62 ; p<0.001$ ), and long wingtips (higher value of digit III/(digit $\mathrm{V}+$ forearm); $t=9.62$, d.f. $=62 ; p<0.001$ ). Thus, they seem to be well-adapted for fast but highly maneuverable flight, helpful in seizing insects by aerial hawking or by flycatching (Jones and Rayner 1989, Jones 1990). Wing shapes of some of the most archaic Microchiroptera are similar to that of some rhinolophids (Habersetzer and Storch 1987, Norberg 1989).

The main functional effect of the second principal component concerns the separation of most of the rhinolophids whose center of distribution is in humid areas (e.g., tropical rain forests of southeast Asia and Africa) from those inhabiting dry areas (e.g., Mediterranean sclerophyllous and African savanna woodlands). This component has its highest positive correlations with the greatest horseshoe breadth and palatal length. All rhinolophids hunt with their mouths closed, while emitting ultrasonic pulses through their nostrils lying in the center of the horseshoe (Möhres 1953). The distance between the nostrils is equal to half the wavelength (Konstantinov et al. 1988). As already shown for several bat families (Novick 1977, Heller and Helversen 1989, but ef. Jones et al. 1992), a correlation between body size and call frequency exists in the Rhinolophidae $(r=-0.557$, d.f. $=22, p<0.01$; Fig. 6A). An even more significant relationship $(r=-0.822$, d.f. $=$ $22, p<0.001$ ) exists between call frequency and the greatest horseshoe breadth (Fig. 6B). Evidently, bats with wide horseshoes emit lower-frequency calls. A longer palate (larger resonant body) may be important in producing deeper frequencies as well $(r=-0.788$, d.f. $=22, p<0.001)$. These correlations are highly significant and of the same sign when relative dimensions of the horseshoe and palate (in relation to the greatest skull length) are used. Relative forearm length is the only exception $(r=0.263$, d.f. $=22, p>0.05)$. Lower-frequency sounds have 
longer wavelengths than do higher-frequency sounds, and provide poor resolution of target detail and are also less directional (Shimozawa et al. 1974) and less subject to environmental attenuation (Griffin 1971, Lawrence and Simmons 1982). Within the genus Rhinolophus, species from drier climates have higher average call frequencies than do species from tropical rain forests (Heller and Helversen 1989). Relatively wide horseshoes in $R$. luctus, $R$. trifoliatus, $R$. yunanensis, $R$. pearsonii, R. subrufus, and R. rufus (Fig. 1A), for example, may indicate that these bats are adapted to hunt in humid areas. Fenton and Fullard (1979) suggested that high frequencies used in echolocation by most of the Rhinolophidae and Hipposideridae may have evolved to avoid easy detection by moths. As horseshoe breadth increases, relative skull size decreases, as evidenced by high negative loadings on height and breadth of braincase, foramen magnum width, and least interorbital breadth (Table 1). Small brain sizes suggest difficulties in the location of food resources which are isolated in small pockets (Eisenberg and Wilson 1978; see also Stephan et al. 1981, Findley and Wilson 1982).

The third principal component contrasts jaw and some cranial characters with palatal and ear lengths (Table 1). The structure of the mandible and palate is related to prey selection. The pinnae serve an important function in echolocation and affect the detection and capture of prey (Fenton 1972, Norberg 1987). They may also provide additional uplift during flight (Vaughan 1966). Few bats with
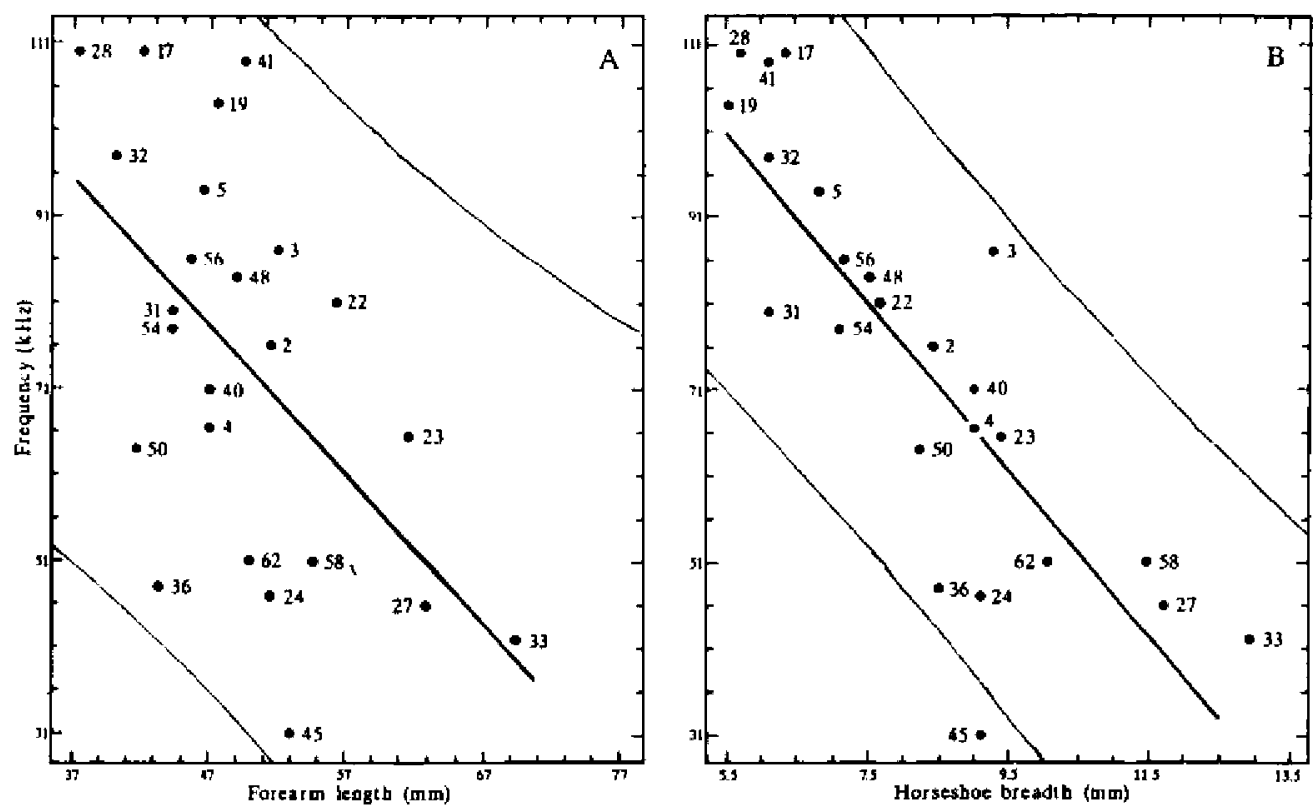

Fig. 6. Relationships between call frequency of rhinolophid bats and A, forearm length (regression line: $y=-1.73 x+159.75 ; r=-0.557, p<0.01) ;$ and $B$, greatest horseshoe breadth $(y=-9.75 x+154.85$; $r=-0.822, p<0.001$ ). Call frequencies taken from Heller and Helversen (1989). The arca between two curves indicates the $95 \%$ prediction limit of the regression slope. Species numbered as in Fig. 1. 
high values on this component are specialized for localization and gleaning small prey from foliage or from the ground.

Andersen (1905b) regarded unshortened palate, retention of $\mathrm{P}^{2}$ and $\mathrm{P}_{3}$ in line with toothrows, subequal metacarpals (4th a trifle longer), and three mental grooves to be primitive features for the Rhinolophidae. Within the ferrumequinum group, from about 6 million years ago during early Pliocene ( $R$. kowalskii) to recent Holocene ( $R$. ferrumequinum), the palate became reduced by about $20 \%$, yet the rate of change varied considerably. The shortening of the palate was rapid in the first half of the Pliocene, slowed in the latter half of this period, and accelerated considerably in the Pleistocene (Wołoszyn 1987). Considerable reduction of the jaw apparatus occurred in a comparatively short geological period. The process involved the small premolars, the postdental part of the mandible and of the skull (Sigé 1978, Topál 1979, Woloszyn 1987). The coronoid process of rhinolophids has not changed a great deal, and in the Tertiary, it was as low as it is in several recent forms. High coronoid processes are characteristic of members of the sister family Hipposideridae (Friant 1963). These trends, in conjunction with the results of functional and phylogenetic analyses, suggest that a close ancestor of rhinolophids most probably lived in tropical rain forests in the Oriental region. It flew slowly, emitted relatively low-frequency sounds, and seized large but soft prey.

Acknowledgments: My sincerest thanks go to Drs R. D. Owen, K. F. Koopman, and three anonymous reviewers for criticizing previous versions of the manuscript. I am also grateful to $P$. Bates, Earl of Cranbrook, J. Fairon, A. Frenkiel, Z. Frenkiel, D. L. Harrison, J. E. Hill, V. Hobbs, and A. M. Hutson for help during my stay in Great Britain and Belgium. Dr. M. R. Willig kindly improved style of the manuscript. Dr. C. Smeenk helped with rare and old publications.

The following institutions are gratefully acknowledged for use of specimens: American Museum of Natural History; Bishop Museum; British Museum of Natural History; California Academy of Sciences; Hungarian Natural History Museum; Harrison Zoological Museum (Sevenoaks, Great Britain); Institut royal des Sciences naturelles de Belgique; Institute of Systematic and Experimental Zoology, Polish Academy of Sciences; Kishio Macda's collection (Hozumi, Japan); Koninklijk Museum voor Midden-Afrika (Tervuren, Belgium); Kaffrarian Museum (King William's Town, South Africa); Natural History Museum of Los Angeles County; Museum Alexander Koenig; Zoological Museum of Lomonosov's University (Moscow, Russia); Muséum d'Histoire naturelle Genève; Muséum national d'Histoire naturelle (Paris, France); Museum of Victoria (Natural History and Anthropology) (Melbourne, Australia); Museu m of Vertebrate Zoology, University of California, Berkeley; Naturhistorisches Museu m Wien; Osaka City University Medical School (Osaka, Japan); Rijksmuseum van Natuurlijke Historie (Leiden, Holland); Senckenberg Museum; Transvaal Museum (Pretoria, South Africa); National Museum of Natural History, Smithsonian Institution; Instituut voor Taxonomische Zoölogie (Zoölogisch Muscum) (Amsterdam, Holland).

This study was made possible by the Royal Society of London and the Polish Academy of Sciences.

\section{References}

Abbott L. A., Bisby F. A. and Rogers D. J. 1985. Taxonomic analysis in biology. Computers, models, and databases. Columbia Univ. Press, New York: 1 - 336.

Aellen V. 1959. Contribution à l'étude de la faune d'Afganistan. 9. Chiroptères. Revue suisse Zool. 66: $353-386$.

Aellen V. 1973. Un Rhinolophus nouveau d'Afrique centrale. Period. biol. 75: $101-105$.

Aellen V, and Brosset A. 1968. Chiroptères du sud du Congo (Brazzaville). Revue suisse Zool. 75: $435-458$. 
Andersen K. 1905a. A list of the species and subspecies of the genus Rhinolophus, with some notes on their geographical distribution. Ann. Mag. nat. Hist., Ser. 7, 16: 648-662.

Andersen K. 1905b. On some bats of the genus Rhinolophus, with remarks on their mutual affinities, and descriptions of twenty-six new forms. Proc. zool. Soc. Lond. 2: 75 - 145.

Andersen K. 1905c. On the bats of the Rhinolophus arcuatus group, with descriptions of five new forms. Ann. Mag. nat. Hist., Ser. 7, 16: $281-288$.

Andersen K. 1905d. On the bats of the Rhinolophus macrotis group, with descriptions of two new forms. Ann. Mag. nat. Hist., Ser. 7, 16: $289-292$

Andersen K. 1905e. On the bats of the Rhinolophus philippinensis group, with descriptions of five new species. Ann. Mag. nat. Hist., Ser. 7, 16: $243-257$.

Andersen K. 1907. Chiropteran notes. Annali Mus. civ. Stor. nat. Genova, Ser. 3, 3: 5- 45.

Andersen K. 1918. Diagnoses of new bats of the families Rhinolophidae and Megadermatidae. Ann. Mag. nat. Hist., Ser. 9, 2: 374-384.

Andersen K. and Matschie P. 1904. Uebersicht einiger gengraphischen Formen der Untergattung Euryalus. Sber. Ges, naturf. Freunde Berl. 1904: 71 - 83.

Ando K., Tagawa T. and Uchida T. A. 1980. Karyotypes of Taiwanese and Japanese bats belonging to the families Rhinolophidae and Hipposideridae. Cytologia 45: 423-432.

Andö K., Yasuzumi F., Tagawa A. and Uchida T. A. 1983. Further study on the karyotypic evolution in the genus Rhinolophus (Mammalia: Chiroplera). Caryologia 36: $101-111$.

Archer M., Godthelp H., Hand S. J. and Megirian D. 1989. Fossil mammals of Riversleigh, rorthwestern Queensland: preliminary overview of biostratigraphy, correlation and environrental change. Aust. Zool. 25: $29-65$

Arnold M. L., Honeycutt R. L., Baker R. J., Sarich V. M. and Jones J. K., Jr. 1982. Resolving a phylogeny with multiple data sets: a systematic study of phyllostomoid bats. Occas. Papers Mus. Texas Tech Univ. 77: $1-15$.

Baagse H. J. 1987. The Scandinavian bat fauna: adaptive wing morphology and free flight in the field. [In: Recent advances in the study of bats. M. B. Fenton, P. Racey and J. M. V. Rayner, eds]. Cambridge Univ. Press, Cambridge: $57-74$

Baker R. J. and Bickham J. W. 1980. Karyotypic evolution in bats: evidence of extensive and conservative chromosomal evolution in closely related taxa. Syst. Zool. 29: $239-253$.

Baker R. J., Hood C. S. and Honeycutt R. L. 1989. Phylogenetic relationships and classification of the higher categories of the New World bat family Phyllostomidae. Syst. Zool. 38: 228-238.

Belcheva R. G., Topashka-Ancheva M. N. and Bisserkov V. 1990. Karyological studies of Rhinoliphus ferrumequinum and Rhinolophus hipposideros (Rhinolophidae, Chiroptera) from Bulgaria. C. $\mathbf{r}$. Acad. bulg. Sci. 43: $81-83$

Bergmans W. and van Bree P. J. H. 1986. On a collection of bats and rats from the Kangean Islands, Indonesia (Mammalia: Chiroplera and Rodentia). Z. Säugetierk. 51: $329-344$.

Bogdanowicz W. and Owen R. D. 1992. Phylogenetic analyses of the bat family Rhinolophidae. Z. zool. Syst. Evolut.-forsch. 30: $142-160$.

Butler P. M. 1978. Insectivora and Chiroptera. [In: Evolution of African mammals. V. J. Maglit and H. B. S. Cooke, eds]. Harvard Univ. Press, London: $56-68$.

Capanna E., Civitelli M. V. and Conti L. 1967. I cromosomi somatici del pipistrello "Ferro di ccvallo minore" (Mammalia - Chiroplera). Atti Accad. naz. Lincei Rc. 42: 125 - 128 .

Sorbet G. B. and Hill J. E. 1991. A world list of mammalian species. Brd ed. Nat. Hist. Mus. Publ and Oxford Univ. Press, London: $1-243$.

Dulic B. 1980. Chromosomes of three species of Indian Microchiroptera. Myotis 18-19: 76-82

Eisenberg J. F. and Wilson D. E. 1978. Relative brain size and feeding strategies in the Chirotera. Evolution 32: $740-751$.

Fattaev M. D. and Kuliev G. K. 1978. [Chromosomal rearrangements and evolution of bat karyoypes in the genus Rhinolophus]. Izv. Akad. Nauk azerb. SSR, Biology 2: 66 - 71. [In Rusiam, Azerbaijanian summary] 
Fenton M. B. 1972. The structure of aerial-feeding bat faunas as indicated by ears and wing elements. Can. J. Zool. 50: $287-296$.

Fenton M. B. 1989. Head size and the foraging behaviour of animaleating bats. Can. J. Zool. 67: $2029-2035$.

Fenton M. B. and Fullard J. H. 1979. The influence of moth hearing on bat echolocation strategies. J. comp. Physiol. 132A: $77-86$.

Findley J. S. 1973. Phenetic packing as a measure of faunal diversity. Am. Nat. 107; $580-584$.

Findley J. S. 1976. The structure of bat communities. Am. Nat. 110: $129-139$.

Findley J. S. and Wilson D. E. 1982. Ecological significance of chiropteran morphology. [In: Ecology of bats. T. H. Kunz, ed.]. Plenum Press, New York: 243 - 260.

Flannery T. F. 1989. Origins of the Australo-Pacific land mammalian fauna. Aust. Zool. Rev. 1: $15-24$

Flannery T. F. 1990. The mammals of New Guinea. Robert Brown and Assaciates, Carina: $1-440$.

Freeman P. W. 1979. Specialized insectivory: beetle-eating and moth-eating molossid bats. J. Mammal. 60: $467-479$.

Freeman P. W. 1981. A multivariate study of the family Molossidae (Mammalia, Chiroptera): morphology, ecology, evolution. Fieldiana, Zool. 1316: 1- 173.

Freeman P. W. 1989. Morphometric assessment of the family Emballonuridae and a comparison with biochemical data. Bat Res. News 30:65.

Friant M. 1963. Les Chiroptera (Chauves-Souris). Révision des Rhinolophidae de l'époque tertiaire. Acta zool., Stockh. 44: $161-178$.

Gaisler J. 1971. Systematic review and distinguishing characters of the bats (Chiroptera) hitherto recorded in Afghanistan. Zool. Listy 17: $41-48$.

Goodwin R. E. 1979. The bats of Timor: systemalics and ecology. Bull. Am. Mus. nat. Hist. 163: $73-122$.

Gray J. E. 1866. A revision of the genera of Rhinolophidae, or horseshoc bats. Proc. zool. Soc. Lond. 6: $81-83$

Griffin D. R. 1971. The importance of atmospheric attenuation for the echolocation of bats (Chiroptera). Anim. Behav. 19: 55-61.

Habcrsetzer J. and Storch G. 1987. Klassifikation und funktionelle Flügelmorphologie paläogener Fledermäuse (Mammalia, Chiroptera). Cour. Forsch.-Inst. Senckenberg 91: 117 - 150.

Hall L. S. 1989. Rhinolophidae. [In: Fauna of Austra]ia. Mammalia. D. W. Walton and B. J. Richardson, eds]. Australian Government Publishing Service, Canberra, 1B: 857 - 863.

Hamilton-Smith E. 1974. The present knowledge of Australian Chiroptera. J. Aust. Mammal Soe. 1: $95-108$.

Hamilton-Smith E. 1975. Gondwanaland and the Chiroptera. J. Aust. Mammal Soc. 1: 382 - 383.

Hanák V. 1969. Zur Kenntnis von Rhinolophus bocharicus Kastchenko et Akimov, 1917 (Mammalia: Chiroptera). Vest. ¿sl. Spol. zool. 33: $315-327$.

Hand S. 1984. Bat beginnings and biogeography: a southern perspective. [In: Vertebrate zoogeography and evolution in Australia (Animals in space and time). M. Archer and G. Layton, eds]. Hesperian Press, Carlisle: 853 - 904 .

Harada M., Yenbutra S., Yosida T. H. and Takada S. 1985. Cytogenetical study of Rhinolophus bats (Chiroptera, Mammalia) from Thailand. Proc. Japan Acad., Ser. B, 61: 455 - 458.

Heller K.-G. and Helversen O. v. 1989. Resource partitioning of sonar frequency bands in rhinolophid bats. Oecologia 80: $178-186$.

Hill J. E. 1972. A note on Rhinolophus rex Allen, 1923 and Rhinomegalophus paradoxolophus Bourret, 1951 (Chiroptera: Rhinolophidae). Mammalia 36: 428 - 434.

Hill J. E. 1983. Bats (Mammalia: Chiroptera) from Indo-Australia. Bull. Br. Mus. nat. Hist, Zool. Ser 45: $103-208$.

Hill J. E. and Schlitter D. A. 1982. Rhinolophidae from New Guinea, with the description of a new subspecies. Ann. Carneg. Mus. 51: $455-464$. 
Hill J. E. and Yoshiyuki M. 1980. A new species of Rhinolophus (Chiroptera, Rhinolophidae) from Iriomote Island, Ryukyu Islands, with notes on the Asiatic members of the Rhinolophus pusillus group. Bull. natn. Sci. Mus., Zool. Ser. 6: $179-189$.

Hinton M. A. C. 1925. Two new nose-leaf bats from Buru. Ann. Mag. nat. Hist., Ser. 9, 16: 255 - 257.

Jones G. 1990. Prey selection by the greater horseshoe bat (Rhinolophus ferrumequinum): optimal foraging by echolocation? J. Anim. Ecol. 59: $587-602$.

Jones G. M., Gordon T. and Nightingale J. 1992. Sex and age differences in the echolocation calls of the lesser horseshoe bat, Rhinolophus hipposideros. Mammalia 56:189-193.

Jones G. and Rayner J. M. V. 1989. Foraging behavior and echolocation of wild horseshoe bats Rhinolophus ferrumequinum and $R$. hipposideros (Chiroptera, Rhinolophidae). Behav. Ecol. Sociobiol. 25: $183-191$.

Kock D. 1973. Merkmalsdifferenzen tropischer Fledermäuse. Z. Säugetierk, 38: $129-143$.

Konstantinov A. I., Makarov A. K., Movcan E. V., Sokolov B. V. and Gorlinskij I. A. 1988. [Echolocation sensory system of horseshoe bats]. Nauka, Leningrad: 1 - 224. [In Russian]

Koopman K. F. 1970. Zoogeography of bats. [In: About bats. A chiropteran biology symposium. B. H. Slaughter and D. W. Walton, eds]. Southern Methodist Univ. Press, Dallas: 29 - 50.

Koopman K. F. 1975. Bats of the Sudan. Bull. Am. Mus. nat. Hist. 154: $353-444$.

Koopman K. F. 1982. Rhinolophidae. [In: Mammal species of the world: a taxonomic and geographic reference. J. H. Honacki, K. E. Kinman and J. W. Koeppl, eds]. Allen Press, Inc. and Ass. Syst. Coll, Lawrence, Kansas: $136-149$.

Koopman K. F. 1989. Distributional patterns of Indo-Malayan bats (Mommalia: Chiroptera). Am. Mus. Novit. 2942: $1-19$

Lanza B. 1959. Notizie sull'osso peniale dei Chirotteri Europei e su alcuni casi di parallelismo morfologico. Monilore zool. ital. 67: 3 - 14 .

Laurent P. 1940. Le crâne de Rhinolophus maclaudi Pousargues. Bull. Mus. natn. Hist. nat., Ser. 2, 12: $224-231$.

Lawrence B. D. and Simmons J. A. 1982. Measurements of almospheric attenuation at ultrasonic frequencies and the significance for echolocation by bats. J. acoust. Soc. Am. 71: $585-590$.

Lekagul B. and McNeely J. A. 1988. Mammals of Thailand. 2nd ed. Darnsutha Press, Bangkok: $1-758$.

Lincoln R. J., Boxshall G. A. and Clark P. F. 1982. A dictionary of ecology, evolution, and systematics. Cambridge Univ. Press, Cambridge: 1 - 298.

Matschie P. 1901. Ueber rumänische Säugethiere. Sber. Ges. naturf. Freunde Berl. 1901(8): $220-238$.

Maynard Smith J, and Savage R. J. G. 1959. The mechanics of mammalian jaws. Sch. Sci. Rev. 40: $289-301$.

Mayr E. 1969. Principles of systematic zoology. MeGraw-Hill Book Company, New York: xi+1-428.

McFarlane D. A. and Blood B. R. 1986. Taxonomic notes on a collection of Rhinolophidae (Chiroptera) from Northern Thailand, with a description of a new subspecies of Rhinolophus robinsoni. Z. Säugetierk. 51: $218-223$.

MeNab B. K. 1971. The structure of tropical bat faunas. Ecology 52: 352-358.

Meester J. A. J., Rautenbach I. L., Dippenaar N. J, and Baker C. M. 1986. Classification of southern African mammals. Transv. Mus. Monogr. 5: 1 - 359.

Möhres F. P. 1953. Über die Ultraschallorientierung der Hufeisennasen (Chiroptera-Rhinolophidae). Z. vergl. Physiol. 34: $547-588$.

Nabhitabhata J. 1986. Food of Thai bats. Preliminary study of the food habits of insectivorous bats from Thailand. [In: Contributions to the knowledge of the bats of Thailand. H. Felten, ed.]. Cour. Forsch.-Inst. Senckenberg, 87: $55-71$.

Najdu K. N. and Gururaj M. E. 1984. Karyotype of Rhinolophus luctus (ord: Chiroptera). Curr. Sci. 53: $825-826$. 
Norberg U. M. 1987. Wing form and Might mode in bats. [In: Recent advances in the study of bats. M. B. Fenton, P. Racey and J. M. V. Rayner, eds]. Cambridge Univ. Press, Cambridge: $43-56$.

Norberg U. M. 1989. Ecological determinants of bat wing shape and echolocation call structure with implications for some fossil bats. [In: European bat research 1987. V. Hanák, I. Horácek and J. Gaisler, eds]. Charles Univ. Press, Praha: $197-211$.

Novick A. 1977. Acoustic orientation. [In: Biology of bats. W. A. Wimsatt, ed.]. Academic Press, New York 3: $74-289$.

Owen R. D. 1987. Phylogenetic analyses of the bat subfamily Stenodermatinae (Mammalia: Chiroptera). Spec. Publ. Mus. Texas Tech Univ. 26: 1-65.

Owen R. D. 1988. Phenetic analyses of the bat sublamily Stenodermatinae (Chiroplera: Phyllostomidae). J. Mammal. 69: 795 - 810.

Peters W. 1867. On some Mammalia collected by Capt. A. C. Beavan, C.M.Z.S., at Moulmein, Burmah. Proc. zool. Soc. Lond. (1866): 426 - 429.

Peters W. 1871. Über die Gattungen und Arten der Hufeisennasen, Rhinolophi. Mber. Königlich Preuss. Akad. Wiss. Berlin: $301-331$.

Pierson E. D. 1986. Molecular systematics of the Microchiroptera: higher taxon relationships and biogeography. Ph. D. dissert., Univ. California, Berkeley: $1-262$.

Qumsiyeh M. B., Owen R. D. and Chesser R. K. 1988. Differential rates of genic and chromosomal evolution in bats of the family Rhinolophidae. Genome 30: 326 - 335 .

Qumsiyeh M. B., Schlitter D. A. and Disi A. M. 1986. Now records and karyotypes of small mammals from Jordan. Z. Säugetierk. 51: 139 - 146.

Rautenbach I. L. 1986. Karyotypical variation in Southern African Rhinolophidae (Chiroptera) and non-geographic morphometric variation in Rhinolophus denti Thomas, 1904. Cinbebasia, Ser. A, 8: $130-139$.

Rohlf F. J. 1974. Methods of comparing classifications. A. Rev. Ecol. Syst. 5: $101-113$.

Sanborn C. C. 1939. Eight new bats of the genus Rhinolophus. Fld Mus. Nat. Hist., Zool. Ser. 24: $37-43$.

Sawada I. and Harada M. 1988. Vampirolepis isensis (Cestoidea: Hymenolepididae) from Rhinolophus monoceros and the systematic connection between Formosan and Japanese horseshoe bats. Proc. Jap. Soc. syst. Zool. 37: $20-23$.

Shimozawa T., Suga N., Hendler P. and Schuetze S. 1974. Directional sensilivity of echolocation system in bats producing frequency modulated signals. J. exp. Biol. 60: 53-69.

Sigé B. 1978. La poche à phosphate de Ste-Néboule (Lot) et sa faune de vertebrés du Ludien supérieur. 8 - Insectivores et chiroptères. Palaeovertebrata 8: 243 - 268.

Sinith J. D. 1972. Systematics of the Chiropteran family Mormoopidae. Mise. Publs Mus. nat. Hist. Univ. Kans. 56: $1-132$.

Smith J. D. and Hood C. S. 1980. Additional material of Rhinolophus ruwenzorii Hill, 1942 with comments on its natural history and taxonomic status. [In: Proceedings of the Firth International Bat Research Conference. D. E. Wilson and A. L. Gardner, eds]. Texas Tech Press, Lubbock: $163-171$

Sneath P. H. A. and Sokal R. R. 1973. Numerical taxonomy. W. H. Freeman and Company, San Francisco: $1-573$.

Stephan H., Nelson J. E. and Frahm H. D. 1981. Brain size comparison in Chiroplera. Z. zool. Syst. Evolut.-forsch, 19: $195-222$.

Tate G. H. H. 1943. Results of the Archbold expeditions. No. 49. Further notes on the Rhinolophus philippinensis group (Chiroptera). Am. Mus. Novit. 1219: $1-7$.

Tate G. H. H. 1946. Geographical distribution of the bats in the Australian Archipelago. Am. Mus. Novit. 1323: $1-21$.

Tate G. H. H. and Archbold R. 1939. Results of the Archbold Expeditions. No. 24. Oriental Rhinolophus, with special reference to material from the Archbold Collections. Am. Mus. Novit. 1036: $1-12$. 
Topál G. 1958. Morphological studies on the os penis of bats in the Carpathian Basin. Annls hist-nat. Mus. natn. hung., Ser. Nov. 9, 50: $331-342$.

Topál G. 1975. Bacula of some Old World leaf-nosed bats (Rhinolophidae and Hipposideridae, Chiroptera: Mammalia). Vertebrata hung. 16: $21-53$.

Topal G. 1979. Fossil bats of the Rhinolophus ferrumequinum group in Hungary (Mamnalia: Chiroptera). Fragm. mineral. palaeontol. 9: 61-101.

van Zyll de Jong C. G. 1984. Taxonomic relationships of Nearctic small-footed bats of the Myotisleibii group (Chiroptera: Vespertilionidae). Can. J. Zool. 62: $2519-2526$.

Vaughan T. A. 1966. Morphology and night characteristics of molossid bats. J. Mamml, 47: $249-260$.

Vaughan T. A. 1972. Mammalogy. W. B. Saunders Company, Philadelphia: $1-463$.

Woloszyn B. W. 1987. Pliocene and Pleistocene bats of Poland. Acta palaeont. pol. 32: 20' -325

Wood D. S. 1983. Character transformations in phenetic studies using continuous morphonetric variables. Syst. Zool. 32: $125-131$.

Yoshiyuki M. 1989. A systematic study of the Japanese Chiroplera. Nat. Sci. Mus., Tokyo: 1 - 242.

Yoshiyuki M. 1990. Notes on Thai mammals. 2. Bats of the pusillus and philippinensis groups if the genus Rhinolophus (Mammalia, Chiroptera, Rhinolophidae). Bull. natn. Sci. Mus., Zoul. 16: $21-40$.

Zhang W. 1985. A study on the karyotypes in four species of bat (Rhinolophus). Acta theriol. in. 5 : $95-101$

Zima J. 1982. Karyotypy tłł druhủ vrápencư (Rhinolophus ferrumequinum, Rh. hipposideroi, $R h$. euryale) z Ceskoslovenska. Lynx, N.S., 21: 12I - 124.

Zima J., Volleth M., Horácek I., Cervený J., Cervena A., Prücha K., and Macholan M. In sress. Comparative karyology of rhinolophid bats (Chiroptera: Rhinolophidae). [In: Prague studes in mammalogy. I. Horáček and V. Vohralik, eds]. Charles Univ. Press, Praha.

Received 8 September 1992, accepted 15 September 1992. 